\title{
EDIÇÃO E FICÇÃO
}

João Gonçalves Ferreira

Christófaro Silva* *joaogfsilva@gmail.com

Mestre em Teoria da Literatura pela UFMG.
RESUMO: Este artigo pretende analisar o modo como alguns procedimentos editoriais que culminaram na publicação do Diário do hospício de Lima Barreto entram em choque com o próprio texto do autor carioca, que desestabiliza os parâmetros genéricos sugeridos pela edição, criando uma tensão que não só torna difícil para o leitor a decisão entre a aceitação ou não de um pacto autobiográfico como também potencializa os diálogos entre literatura, vida, escritor e personagem que a aparecem.

PALAVRAS-CHAVE: diário de escritor, imagem do escritor, Diário do hospício, Lima Barreto.
ABSTRACT: This article intends to analyze the choices made in some of the editorial procedures that culminated in the publication of Lima Barreto's Diário do hospício (Asylum's Diary). This choices often conflict with some of the characteristics of the text itself, which destabilizes the generic parameters suggested by the edition creating a tension that makes it difficult for the reade to decide on whether he should or should not accept the autobiographical pact. This tension potentializes the dialogues between literature, life, writer and character that take place in this diary.

KEYWORDS: writer's diary, writer's image, Asylum's Diary, Lima Barreto. 
Lima Barreto possui dois diários publicados: O Diário intimo e o Diário do hospício. Os dois diários são bem diferentes. $\mathrm{Na}$ edição que adotamos, o Diário íntimo inicia-se no ano de 1900 e se mantém até o ano de 1921, contendo tanto notas do que seria mais propriamente o diário mantido por Lima Barreto, que se inicia em 1903 com o título de Um diário extravagante, quanto rascunhos e anotações em folhas soltas. Os rascunhos e anotações, referentes principalmente aos anos de 1900, 1906, 1910 e 1914, foram adicionados por Francisco de Assis Barbosa em sua edição de 1956 do Diário íntimo - edição que foi usada como base para o texto que utilizamos, contido no livro Um longo sonho de futuro. Apesar de se estender por um período razoavelmente longo, esse não é um diário muito volumoso, o que já nos deixa entrever a falta de regularidade da prática diarística, no caso de Lima Barreto. Tal fato não impede, no entanto, a grande diversidade das entradas, que variam tanto em seu conteú do quanto em sua forma. Encontramos, aí, entradas curtas e longas, telegráficas ou mais detalhadas, muitas vezes não datadas, cobrindo uma grande variedade temática: notas íntimas, desabafos, rascunhos de ficção, notas sobre eventos cotidianos e importantes eventos históricos, comentário sobre literatura e a vida literária do Rio de Janeiro do início do século XX, anotações de gastos e de distribuição de livros, citações, etc.
Bastante diferente do Diário intimo, o Diário do hospício foi escrito durante sua segunda estadia no Hospício Nacional dos Alienados, onde ficou internado entre 25 de dezembro de 1919 e 2 de fevereiro de 1920, e concebido como um conjunto de anotações que serviriam de fonte para um romance, O cemitério dos vivos, que não chegou a ser concluído. Escrito em uma situação de encarceramento - situação, aliás, que parece ser bastante propícia para o início de diários, na qual são engendrados textos que muitas vezes se encaixam em uma espécie de subgênero ${ }^{1}$-, os escritos desse diário rondam especialmente os aspectos da própria internação. Podemos ler, nesse texto, tanto apontamentos sobre o funcionamento do hospício, os médicos, enfermeiros e pacientes, quanto indagações do escritor sobre sua própria história e situação, além de reflexões sobre a loucura, a ciência e poder. Misturadas aos temas elencados acima, aparecem, ainda, com bastante frequência, considerações sobre a escrita, o escritor e a literatura.

A edição adotada, também baseada na edição de 1956 de Francisco de Assis Barbosa, está divida em dez capítulos que contêm, entre si, diferenças bastante relevantes. Os nove primeiros apresentam uma estrutura mais ou menos regular, cada um contendo uma entrada razoavelmente longa bem desenvolvida, das quais apenas a primeira aparece datada de maneira tradicional. Totalmente diferente dos nove
1. Cf. Didier $(2002$, p. 12) Fernandes (2008) 
2. Usamos, aqui, o termo "luscofusco" como utilizado por “Dilió Maciel (2010, p. 82) em cabotinismo na correspondên e de primeiros, o último capítulo apresenta uma estrutura mais entrecortada e paratática, composta por entradas mais curtas e ligeiras e com datação mais constante (embora não onipresente). Por fim, muitas dessas entradas parecem ter sido desenvolvidas no texto dos nove primeiros capítulos.

Nesses textos, especialmente no Diário do hospício, podemos ver constantemente um deslocamento de Lima Barreto em direção a outros escritores e personagens. Esse movimento constrói sua imagem operando uma espécie de lusco-fusco $^{2}$ entre vida e literatura, escritor e personagem, no qual uma separação estanque entre tais âmbitos torna-se impossível. Esse processo se opera principalmente em relação a Dostoiévski, Cervantes e Dante.

No primeiro capítulo do Diário do hospício, que ainda contém uma datação tradicional de diário (04 de janeiro de 1920), ao descrever o modo como chegou ao hospício e o tratamento recebido nos dias anteriores, escreve:

Passei a noite de 25 no pavilhão, dormindo muito bem, pois a de 24 tinha passado em claro, errando pelos subúrbios, em pleno delírio.

Amanheci, tomei café e pão e fui à presença de um médico, que me disseram chamar-se Adauto. Tratou-me com indife- rença, fez-me perguntas e deu a entender que, por ele, me punha na rua.

Voltei para o pátio. Que cousa, meu Deus! Estava ali que nem um peru, no meio de muitos outros, pastoreado por um bom português, que tinha um ar rude, mas doce e compassivo, de camponês transmontano. Ela já me conhecia da outra vez. Chamava-me você e me deu cigarros. Da outra vez, fui para a casa-forte e ele me fez baldear a varanda, lavar o banheiro, onde me deu um excelente banho de ducha de chicote. Todos nós estávamos nus, as portas abertas, e eu tive muito pudor. Eu me lembrei do banho de vapor de Dostoievski, na Casa dos Mortos.

Quando baldeei, chorei; mas lembrei de Cervantes, do próprio Dostoievski, que pior deviam ter sofrido em Argel e na Sibéria.

Ah! A Literatura ou me mata ou me dá o que eu peço dela. ${ }^{3}$

Acreditamos que esse trecho apresenta um processo de identificação de Lima Barreto com outros escritores, que acaba por constituir uma espécie de passado literário, como um conjunto de retalhos ou uma constelação. O que o torna mais interessante para nós é que nele esse deslocamento em direção ao que Lima Barreto certa vez chamou de "grande Humanidade” se dá via biografia, e não através de qualquer característica que poderíamos considerar como mais propriamente literária, como estilo de escrita, escolha de temas, método de trabalho, etc. A rede de relações construída por
3. BARRETO. Um longo sonho do futuro: diários, cartas, entrevistas e confissões dispersas, p. 154 
4. Nesse sentido, pode ser importante lembrarmo-nos de que uma das principais bandeiras de muitos dos escritores das primeiras décadas do séc. XX eram a profissionalização do escritor e o abandono da vida literária ligada à boemia. Cf. Broca (2005, p. 39-54, 285-314).

5. BARRETO, Um longo sonho do futuro: diários, cartas, entrevistas e confissões dispersas, p. 154.
Lima Barreto, que parece querer conectar três existências inteiras a partir de eventos biográficos repetidos, parece servir tanto como uma espécie de consolo diante de sua internação quanto como um modo de afirmar-se enquanto escritor. Afirmar-se enquanto escritor através da ligação de sua vida e de seus sofrimentos à vida e aos sofrimentos registrados na biografia de outros escritores parece operar uma espécie de ressignificação da própria palavra "escritor", que não pode mais significar simplesmente a escolha por um ofício ou ser a palavra que dá conta de nomear aquele que tem a escrita como principal atividade 4 , mas deve agora se envolver de todo um imaginário que liga o escritor a algum tipo de essência espiritual e destino trágico - "Ah! A Literatura ou me mata ou me dá o que eu peço dela"

Em outro trecho do Diário do hospício, encontrado no fim do segundo capítulo, que contém a datação "de 29-12-19 a 4-1-20" e parece compreender mais de uma entrada, já que contém duas ancoragens temporais diferentes, Lima Barreto aproxima-se de mais um escritor canônico: Dante.

Estou entre mais de uma centena de homens, entre os quais passo como um ser estranho. Não será bem isso, pois vejo que são meus semelhantes. Eu passo e perpasso por eles como um ser vivente entre sombras - mas que sombras, que espíritos?! As que cercavam Dante tinham em comum o stock de idéias indispensáveis para compreendê-lo; estas não têm mais um para me compreender, parecendo que têm um outro diferente, se tiverem algum. ${ }^{6}$

Mais uma vez, vemos Lima Barreto se aproximar de um escritor canônico para, de algum modo, organizar a sua vivência, em um movimento que, como na citação anterior, parece servir também para que Lima possa afirmar-se enquanto escritor, separando-se quase que ontologicamente dos outros internos, que, aqui, não passam de sombras rodeando esse ser vivente que é o próprio Lima Barreto.

Além disso, podemos perceber que nestes trechos se opera, subterraneamente, um processo que acaba por criar uma espécie de zona de indiferenciação entre escritor e personagem, vida e ficção, na qual a vida de Lima Barreto se configura também como narrativa ficcional, na qual o próprio Lima Barreto passa a ocupar, ao mesmo tempo, o lugar do indivíduo empírico e do protagonista.

Voltando às citações de Lima Barreto, podemos perceber que o signo Dante, no qual Lima Barreto se enreda, pode apontar tanto para o Dante personagem da Divina Comédia, que desce ao Inferno e circula entre sombras, como ao Dante poeta e a sua poesia, os quais seria possível compreender a partir das ideias colocadas nas bocas das inúmeras sombras de seu poema. De modo análogo, ao dizer lembrar-se de
6. BARRETO, Um longo sonho do futuro: diários, cartas, entrevistas e confissões dispersas, p. 160. 
7. FREYRE, 1961, p. 9.

8. Ibidem, p. 16.

9. LIMA, 2001, p. 34 .

10. BARRETO. Um longo sonho do futuro: diários, cartas, entrevist e confissões dispersas, p. 127
Dostoiévski, nas Memórias da casa dos mortos, Lima Barreto provoca uma indiferenciação entre as instâncias da vida do escritor (Dostoiévski, exilado na Sibéria) e de seu romance, que trata de condenados na prisão da Sibéria, mas no qual Dostoiévski não figura como personagem.

Uma leitura atenta da crítica de Lima Barreto nos permite perceber, inicialmente com bastante surpresa, que diverso dos predicados relacionados a Lima Barreto têm relação com algumas das aproximações aqui apresentadas.

Gilberto Freyre, em seu prefácio ao Diário intimo, afirma que Lima Barreto era um "homem do trópico com algo de russo dos gelos", e que ele havia sido "uma espécie de personagem de romance russo desgarrado nos trópicos" ${ }^{8}$. Oliveira Lima, em artigo publicado no Estado de S. Paulo ainda em 1916, compara Policarpo Quaresma a Dom Quixote9 . Lima Barreto, aliás, indica tal crítica em seu diário, em uma not satisfeita: "Os críticos generosos só se lembravam diante dele do Dom Quixote" ${ }^{10}$. No grande livro de Osman Lins sobre o espaço na obra de Lima Barreto, no entanto, a comparação entre Quixote e Quaresma dá um salto, se transferindo para a figura do próprio Lima Barreto:

O Pimpinela Escarlate, que convive com os nobres e os combate ocultamente, não constituiria para ele um modelo de ação. O seu modelo seria o Dom Quixote, defensor dos pobres e ofendidos, leitor exaltado, sonhador de perfeições, franco no falar e no agir, ingênuo, vilipendiado - e nem sequer lhe faltaram, aproximando-o ainda mais do modelo, o celibato e a loucura. ${ }^{11}$

Não acreditamos que seja possível (ou, mesmo, conveniente) traçar algum tipo de rota de fonte-influência para este tipo de circulação de textos e imagens. Gostaríamos apenas de deixar transparecer a maneira como esses diversos trechos se relacionam e o modo como se diferenciam. Podemos perceber que as passagens de Gilberto Freyre, em que Lima Barreto não só é comparado a um homem russo, mas também, explicitamente, a um personagem de romance russo, ecoam o fragmento de seu Diário do hospício em que o escritor aproxima-se de Dostoiévski e de sua obra. Por outro lado, as afirmações de Freyre, nas quais a dimensão fictícia da figura do escritor aparece de forma bastante explícita, parecem reforçar a indiferenciação que percebemos na equação vivência de Dostoiévski/Memórias da casa dos mortos, fazendo, assim, com que a dimensão de personagem do escritor, com toda sua carga simbólica, se estabeleça com mais força. De modo análogo, a rede de relações entre Lima Barreto, Policarpo Quaresma, Cervantes e Dom Quixote, que podia apenas ser entrevista no texto do diário, parece se colocar explicitamente enquanto uma relação de textos, ficções e personagens nas palavras de Osman Lins. Dom Quixote, o
11. LINS. Lima Barreto e o espaço romanesco, p. 26

EM TESE

BELO HORIZONTE

v. 19

N. 1

JAN.-ABB. 2013 SILVA. Edição e ficção

P. 276-287

\section{Tradução e Ediç̧ão}


grande paradigma de leitor tomado pelas ilusões da literatura, ao lado de Madame Bovary, se torna aqui modelo para Lima Barreto, a quem é dada, agora, uma bela carga de bovarismo, sobre o qual tanto escreveu em seu Diário íntimo.

Não deixa de ser interessante, além disso, que tanto as palavras de Freyre quanto as de Osman Lins apontem para uma grande carga de desajuste ou deslocamento (em Osman Lins, acompanhada de boa dose de carinho ou empatia) que continuam a fazer rodar uma série de imagens as quais ligam Lima Barreto ao topos do escritor marginal, incompreendido, ligado intensamente à escrita por vocação ou destino. Além de ecoarem em seus diários, tais considerações aparecem também em diversos outros críticos de sua obra. Poderíamos citar, como exemplo emblemático, a biografi escrita por Francisco de Assis Barbosa ${ }^{12}$, em que a vida de Lima Barreto é narrada como uma tragédia anunciada ou como uma curva ascendente que, no entanto, iniciou cedo demais seu declínio.

Tendo em vista essa ideia de imagem do escritor e seu potencial para colocar-se como uma espécie de lusco-fusco entre vida e obra, tentaremos pensar de que modo as decisões editoriais afetam sua construção, muitas vezes poten cializando o embaralhamento das instâncias da literatura e da vida, especialmente no Diário do hospício.
Os estudos acerca dos diários de escritor geralmente possuem uma parte dedicada aos problemas de sua edição. No entanto, como podemos ver em Lis ${ }^{13}$, Didier ${ }^{14}$ e Marty ${ }^{15}$, tais considerações acerca da edição levam muito mais em consideração o que é cortado ou censurado do que o que vem a ser adicionado ou colado à edição final. Em nosso caso, a edição final não pode ser facilmente conectada a um tipo absoluto de intenção autoral, adquirindo antes o caráter de uma montagem editorial.

Há uma primeira série de deslocamentos que acreditamos significativa o bastante para não ser desconsiderada: os trânsitos dos manuscritos da esfera privada para a esfera pública e para a esfera institucional. A partir de textos de Maria Knabben ${ }^{16}$ e Francisco de Assis Barbosa ${ }^{17}$, podemos reconstituir rapidamente essa série de deslocamentos. Após a morte de Lima Barreto, sua biblioteca, seus bens pessoais e diversos manuscritos ficaram sob a guarda de sua irmã Evangelina. Passados mais de vinte anos, nos quais uma mudança de residência teria causado a desorganização dos papéis e possivelmente a perda de alguns documentos, Francisco de Assis Barbosa teria resgatado estes materiais, tendo sido incumbido pelo editor Zélio Valverde, em 1945, de organizar as obras completas do escritor. Esse primeiro empreendimento editorial acabou malogrado, e os primeiros resultados das pesquisas de Francisco de Assis Barbosa foram publicados
13. LIS, 1996, p. 171-178.

14. DIDIER, 2002, p. $24 ; 144-147$

15. MARTY, 1985 , p. 203-204 
somente em 1953, pela editora Mérito. Essa primeira publicação, em volume único, incluía o Diário íntimo, o Diário do hospício e o Cemitério dos vivos. Em 1956, quando a editora Brasiliense publica as Obras completas de Lima Barreto, essa três obras são reeditadas e aumentadas, tendo sido desmembradas em dois volumes - o primeiro contendo o Diário in timo e o segundo contendo o Diário do Hospício e o Cemitério dos vivos. Os manuscritos, por sua vez, foram comprados pela Biblioteca Nacional em 1949, formando a Coleção Lima Barreto, parte integrante da Seção de Manuscritos, aberta à consulta pública.

Podemos pensar, primeiramente, na interdependência entre esses movimentos e o estabelecimento de Lima Barreto no cânone da literatura nacional. Por um lado, o interesse pela publicação de seus escritos íntimos e pela conservação de seus documentos pela Biblioteca Nacional depende de uma imagem de escritor bem estabelecida. Como já notou, por exemplo, Marília Rothier Cardoso, os manuscritos guardados pelas sociedades são os de obras e autores já inscritos no cânone, e, embora a descontinuidade dos arquivos e o desmantelamento do conceito de obra-prima abalem os valores canônicos, o trabalho com manuscritos sempre pode conter a armadilha do fetichismo do autor, da distorção do sujeito e da mistificação da arte ${ }^{18}$. Por outro lado, os mesmos gestos de publicação e institucionalização de documentos intimos servem para a monumentalização de uma imagem do escritor e do valor de sua obra.

Em ambos os diários, podemos ver, ainda, modificações bastante grandes entre as edições de 1953 e 1956 (que se estabeleceu como uma espécie de versão "definitiva”), além do uso de documentos mais ou menos heterogêneos em sua construção. Em ambos os diários, a montagem e as modificações levadas a cabo podem levantar questões teóricas bastante relevantes para o nosso estudo.

A edição do Diário intimo de 1953 não contém, em relação à edição de 1956, principalmente, diversos rascunhos e tentativas literárias. Segundo a exposição dos procedimentos editoriais da edição adotada, foram incluídos, na edição de 1956, capítulos inteiros referentes aos anos de 1900, 1906, 1910 e 1914 . O ano de 1900 contém uma das primeiras tentativas de ficção de Lima Barreto, o ano de 1906 alguns esboços de Vida e morte de Gonzaga de Sá, o ano de 1910 os apontamentos para o Triste fim de Policarpo Quaresma, e o ano de 1914 algumas poucas anotações de teor diverso. Lembremos, também, que o restante do diário já é composto por documentos bastante heterogêneos. No Acervo Lima Barreto, da Biblioteca Nacional, podemos ver que os documentos utilizados para "montar" o Diário íntimo vêm de diversas fontes e coleções. Entre elas, poderíamos citar: uma série de recortes de jornais, transcrições de notícias e anotações, 
utilizadas parcialmente; uma série de cadernetas contendo notas diversas; uma coleção intitulada "Notas de um diário"; documentos soltos que foram incluídos no diário, como a "Carta Circular" em que a Marginália é apresentada, etc. Essa heterogeneidade da montagem torna um pouco obscuros os critérios para a seleção das notas, tornando ainda mais forte a instância da edição. Além disso, a inclusão de diversas páginas de rascunhos e projetos literários na edição de 1956 aumenta radicalmente a presença da literatura e da escrita ficcional em um espaço que, teoricamente, tanto pelo título quanto pelas características mais tradicionalmente ligadas ao diário, pertenceria à intimidade. Diminuindo a intimidade desse espaço, esse gesto impregna de literatura a sua vida e a sua interioridade, reforçando a construção da imagem de um Lima Barreto que é, essencialmente e antes de tudo, um escritor, como se a escrita habitasse cada canto de seus dias e de seus pensamentos.

No Diário do hospício, os problemas são ainda mais complexos, tendo em vista tanto o movimento incessante que nos leva a pensar o escritor ao mesmo tempo como indivíduo empírico e como personagem quanto os próprios problemas concernentes à relação entre discurso autobiográfico e romance nesse diário. Tal complexidade se torna mais patente quando levamos em conta o fato de o Diário do hospício ter sido escrito tendo em vista a confecção de um romance ( $O$ cemitério dos vivos, que acabou ficando incompleto).

Talvez possamos começar observando alguns trechos desse diário que possam nos dar uma ideia dos problemas ai envolvidos. O Diário do hospício parece propor, inicialmente, um pacto autobiográfico implícito. As primeiras linhas desse texto já apresentam um eu-narrador que, pelo título, propõe um gênero textual para o conjunto das anotações, pode ser conectado ao nome do autor inscrito na capa do livro: "Estou no hospício, ou melhor, em várias dependências dele, desde o dia 25 do mês passado. Estive no pavilhão de observações, que é a pior etapa de quem, como eu, entra para aqui pelas mãos da polícia"19. Todo o restante do aparato paratextual que encontramos em diversas de suas edições, ao possibilitarem em algum nível a verificação do ocorrido, servem para reforçar a proposição deste pacto ${ }^{20}$.

No entanto, ao chegarmos ao capítulo V do Diário do hospício, nos deparamos com o seguinte trecho:

Mas na Seção Pinel, aconteceu-me cousa mais manifesta, da estupidez do guarda e da sua crença de que era meu feitor e senhor. Era este um rapazola de vinte e tantos anos, brasileiro, de cabeleira solta, com um ar de violeiro e modinheiro. Estava
19. BARRETO. Um longo sonho do futuro: diários, cartas, entrevistas e confissões dispersas, p. 153.

20. Poderíamos citar, como exemplos, a transcrição de seus prontuários médicos e a de dentro do hospício a jornal de dentro do hospício, ao jornal A Folha. Mesmo que Lejeune, ao falar do pacto autobiográfico, procure levar a discussão para longe da relação entre o texto e o modelo, procurando basearse na ideia de identidade de nome entre autor, narrador e personagem, acreditamos ser difícil negar o quanto tal aparato paratextual favorece, mesmo que através de um procedimento 
21. BARRETO. Um longo sonho do futuro: diários, cartas, entrevistas e confissões dispersas, p. 173. deitado no dormitório que me tinham marcado e ele chegou à porta e perguntou:

- Quem é aí Tito Flamínio?

- Sou eu, apressei-me.

- O Seu S. A. manda dizer que você e sua cama vão para o quarto do doutor $\mathrm{Q} .{ }^{21}$

Esse é o primeiro momento do diário em que se dá, explicitamente, a quebra do pacto autobiográfico. Sem que haja nenhuma separação, aviso ou mudança de registro ou tom, apenas a súbita alternância do nome próprio do narrador-personagem, diferenciado agora do nome do autor impresso na capa, o leitor se vê diante de um impasse. Após esse trecho, há ainda outros momentos em que o pacto é quebrado explicitamente. Este desnudamento repentino da ficcionalização nos força a reler todo o seu texto sob um olhar de dúvida: impossível saber com certeza, após tal rompimento do pacto, em quais pontos o "eu" pode ser identificado com o escritor Lima Barreto, e em quais pontos este "eu" é Tito Flamínio ou Vicente Mascarenhas - nome finalmente escolhido para o protagonista de $O$ cemitério dos vivos.

Lima Barreto descreve, no Diário do Hospício, muitos delírios dos loucos junto aos quais estava internado, bem como os próprios delirantes, acumulando uma espécie de matéria bruta literária. O escritor interessa-se e preocupa-se muito com a clareza e explicação de suas notas, para que não soem como o que ele chama de "incoerência verbal de manicômio"22. Mas há certas aproximações possíveis entre o procedimento de desnudamento repentino da ficção no Diário do Hospício e a descrição que nosso autor que faz da fala de alguns loucos:

É um louco clássico, com delírio de perseguição e grandeza. É um homem inteligente, mas com cultura elementar, e o seu delírio, desde que não se o interrogue pela base, parece à primeira vista a mais pura verdade. No começo, ele me enganou: e julguei certo tudo o que dizia, mas, por fim, ele me revelou toda sua psicose. Por me parecer interessante, eu vou reproduzir as histórias que ele me contou, procurando não quebrar a lógica mórbida com a qual as articulava. Ele é de Sergipe, e chama-se V. de O.23

No emaranhado entre diário e ficção que se constrói nestes textos, o que inicialmente nos engana é a escrita diarística, o pacto que esta firma conosco, a identificação entre o nome do autor e o nome do personagem. Revela-se, então, de supetão, não o psicótico, mas o romancista, o escritor de ficção, abalando, assim, a identidade de nome entre autor, narrador e personagem, não só nos momentos em que o romance aparece descaradamente, mas de todo o texto que a isto sucede ou antecede. E podemos pensar no quanto tal 
efeito de deslocamento textual - que pode ser visto também como um movimento de deslocamento genérico e referencial - tem como princípio justamente os procedimentos levados a cabo na edição do Diário do hospício.

Podemos imaginar a edição dessa série de manuscritos de Lima Barreto como uma espécie de estabilização genérica de seu texto, que é tensionada pela desestabilização genérica desencadeada pela próprio texto. Como afirma Gérard Genette, raramente os textos se apresentam em estado nu. $\mathrm{Na}$ grande maioria das vezes, chegam a nós cercados e prolongados por paratextos, que transformam o texto em livro e pelo qual este se propõe aos leitores enquanto $\mathrm{tal}^{24}$. Dentre esses paratextos, podemos pensar o título como um dos mais importantes. Em nosso caso, se seguirmos a separação proposta por Genette entre títulos temáticos - que informam aquilo de que a obra fala - e títulos remáticos - que dizem o que a obra seria ${ }^{25}$ podemos pensar o título do Diário do hospício como um título misto. Esse título contém tanto indicações genéricas sobre o texto - propondo ao leitor que o leia como um diário - quanto a referência ao "tema" de que fala a obra - uma estadia de Lima Barreto no Hospital Nacional dos Alienados. Como afirma Genette $^{26}$, se parece correto dizer que o leitor não é obrigado a aprovar a indicação genérica proposta pelo título, também não parece ser possível que ele a ignore totalmente. É esta indicação proposta pelo título, escolhido sob a responsabilidade do editor, o que pode acabar por causar os efeitos de sentido que tentamos apresentar nos parágrafos anteriores. Podemos pensar, ainda, na história da edição do Diário do hospício, que em 1953 se encontrava reunido não só ao Cemitério dos vivos como também ao Diário intimo, e em 1956 separa-se do segundo, mantendo-se no mesmo volume que o romance inacabado e recebendo capítulos inteiros de textos inéditos. Entre as adições, estão tanto os capítulos VI a IX, em que o pacto autobiográfico proposto continua a ser explicitamente quebrado agora com maior frequência, quanto o capítulo $\mathrm{X}$, que contém diversos apontamentos que foram reescritos e integrados aos capítulos anteriores e apresenta as características mais tradicionais de um diário: datação mais frequente, entradas curtas, possibilidade de manutenção do pacto autobiográfico, etc.

Podemos, então, pensar em um movimento que distancia o Diário do hospício de um texto autobiográfico. A edição de 1956 separa o Diário íntimo do Diário do hospício e do Cemitérios dos vivos. Conectando diretamente o Diário do Hospício apenas ao Cemitério do vivos, seu romance inacabado, essa edição convida-nos a ler suas anotações feitas no HNA mais como rascunho literário do que como discurso autobiográfico. Soma-se a isso a adição dos capítulos VI a IX, trechos em que o processo de feitura do romance encontra-se cada vez mais evidente. Ao mesmo tempo, no entanto, há ainda a proposição do pacto autobiográfico, não só através 
da manutenção da indicação genérica do título - que, aliás, poderia funcionar agora quase como uma antífrase - como também através da adição das entradas reunidas no capítulo $\mathrm{X}$, mais facilmente relacionáveis ao discurso autobiográfico

Todos esses procedimentos apontam para a tensão entre diário e romance que a edição de 1956 reforça. Parece-nos que tal tensão não pode ser facilmente resolvida, não permitindo ao leitor uma escolha fácil entre a aceitação ou não do pacto proposto. Encontramo-nos, então, mesmo que aqu tenhamos chegado através de caminhos diversos, naquela situação desconfortável sugerida por Paul de Man em seu texto "A autobiografia como des-figuração"27: presos numa porta giratória que pode adquirir aceleração infinita, entre a vida e o romance, entre o escritor e o personagem. No entanto, ao contrário de Paul de Man, que pretende eliminar tal desconforto, acreditamos que é justamente ele um dos efeitos mais interessantes do Diário do hospício, que nos coloca num impasse e aumenta ainda mais a zona de indiferenciação ou de vai-e-vem constante entre personagem escritor e entre vida e obra que parece ser uma das fundações da construção da imagem de Lima Barreto.

\section{REFERÊNCIAS}

ÁVILA, Myriam. Invenção e inventário no diário de escritor 2007. (Texto inédito).
ÁVILA, Myriam. O diário e a diáspora. IPOTESI, v. 15, n. 1, p. 235-240, jun. 2011.

BARBOSA, Francisco de Assis. Nota prévia. In: BARRETO, A H. L. Diário íntimo: memórias. Obras Completas. São Paulo: Brasiliense, 1956. p. 17-21

BARBOSA, Francisco de Assis. A vida de Lima Barreto. Rio de Janeiro: José Olympio, 2002

BARRETO, Afonso Henriques de Lima. Um longo sonho do futuro: diários, cartas, entrevistas e confissões dispersas. 2. ed. Rio de Janeiro: Graphia, 1998

BARRETO, Afonso Henriques de Lima. Cemitério dos vivos: memórias. São Paulo: Brasiliense, 1956.

BROCA, Brito. A vida literária no Brasil - 1900. 5. ed. Rio de Janeiro: José Olympio, 2005

CARDOSO, Marília Rothier. Arquivos literários. In: CONGRESSO INTERNACIONAL DA ASSOCIAÇÃO BRASILEIRA DE LITERATURA COMPARADA, 5., 1996, Rio de Janeiro. Cânones e contexto: Anais. Rio de Janeiro: ABRALIC, 1997, v. 2 .

DE MAN, Paul. A autobiografia como des-figuração. Trad: Joca Wolff. In: Sopro, Florianópolis, n 71, mai/2012 Disponível em: http://www.culturaebarbarie.org/sopro/outros/autobiografia. html\#.UXSbsklHeOw

DIDIER, Béatrice. Le journal intime. Paris: Presses universitaires de France, 2002. 
FERNANDES, Maria Patrício. Para não se acostumar à prisão: a leitura dos diários do hospício de Maura Lopes Cançado, Lima Barreto e Torquato Neto como uma experiência limite. In

CONGRESSO INTERNACIONAL DA ASSOCIACCÃO BRASILEIRA

DE LITERATURA COMPARADA, 11., 2008, São Paulo. Tessituras,

Interações, Convergências. São Paulo: ABRALIC, 2008.

Disponível em: <http://www.abralic.org.br/anais/cong2008/

AnaisOnline/simposios/pdf/005/MARIANA_FERNANDES.pdf>.

Acesso em: 09/05/2013.

FREYRE, Gilberto. Prefácio. In: BARRETO, A. H. L. Diário íntimo 2. ed. São Paulo: Brasiliense, 1961.

GENETTE, Gérard. Paratextos editoriais. Trad: Álvaro Faleiros. Cotia, SP: Ateliê Editorial, 2009.

KNABBEN, Maria Terezinha. O Diário Íntimo de Lima Barreto - da intimidade à historicidade e à literariedade. Eletras, v. 20, n. 20 p. 118-135, jul. 2010

LIMA, Manuel Oliveira. Policarpo Quaresma. In: BARRETO, A. H. L. Prosa Seleta. Rio de Janeiro: Nova Aguilar, 2001. p. 31-34.

LINS, O. Lima Barreto e o espaço romanesco. São Paulo: Ática, 1976

LIS, Jerzy. Le journal d'écrivain en France dans la lère moitié

du XXe siècle: à la recherche d'un code générique. Wyd. 1. ed Poznan: Wydawnictwo Naukowe UAM, 1996

MACIEL, Emílio. Dialética do negaceio: Bildung e cabotinismo na correspondência de Drummond e Mário de Andrade Aletria $v$.

20, n. 2, p. 81-94, ago. 2010.
MARTY, Eric. L'écriture du jour: le Journal d'André Gide. Paris: Éditions du seuil, 1985.

SOUZA, Eneida Maria de. Notas sobre a crítica biográfica. In Crítica Cult. Belo Horizonte: Editora UFMG, 2002.

SOUZA, Eneida Maria de. Saberes narrativos. Scripta, v. 7, n. 14, p. 56-66, sem. 2004. 